\title{
Studies of carbon monoxide dehydrogenase from Oligotropha carboxidovorans
}

Stephanie Dingwall, Jarett Wilcoxen ${ }^{1}$, Dimitri Niks and Russ Hille*

Department of Biochemistry, University of California, Riverside

* Corresponding author at: Department of Biochemistry, 1643 Boyce Hall, University of California, Riverside, CA 92521

E-mail address: russ.hille@ucr.edu (R. Hille)

${ }^{1}$ Present address: Department of Chemistry, University of California, Davis. 


\section{Abstract}

We have undertaken physicochemical studies of the CO dehydrogenase from the aerobe Oligotropha carboxidovorans, probing both the binuclear Mo- and Cu-containing active site where $\mathrm{CO}$ is oxidized to $\mathrm{CO}_{2}$ and the enzyme's $\mathrm{FAD}$, where the reducing equivalents obtained from $\mathrm{CO}$ are transferred to the quinone pool. Regarding the FAD site, we have characterized the semiquinone oxidation state by EPR and identified it to be of the blue neutral form with a linewidth of $20 \mathrm{G}$. The signature long-wavelength absorbance of FADH• is also observed in the absorption spectrum of partially reduced enzyme at low $\mathrm{pH}$. The enzyme exhibits a pH-dependent absorption spectrum in the oxidized state that is lost upon covalent modification of the enzyme by the flavinspecific agent diphenyliodonium cation. The $\mathrm{pH}$ dependence is attributed to Tyr 193 of the FADcontaining CoxM subunit, which sits atop the re face of the isoalloxazine ring in van der Waals contact with it. Electron equilibration among the enzyme's four redox-active centers (including two [2Fe-2S] clusters in addition to the binuclear center and FAD) is found to be pH-dependent, but too fast to be followed using a stopped-flow $\mathrm{pH}$ jump protocol. Electron transfer from the iron-sulfur clusters to the FAD is thus much faster than in other members of the xanthine oxidase family of molybdenum-containing enzymes to which $\mathrm{CO}$ dehydrogenase belongs. Finally, a complex of the binuclear center with bicarbonate has been characterized by EPR, where the absence of observed hyperfine coupling using ${ }^{13} \mathrm{C}$-labeled bicarbonate suggests strongly that the bicarbonate is not directly coordinated to the $\mathrm{Mo}(\mathrm{V})$ of the partially reduced binuclear center.

\section{Highlights}

- $\mathrm{CO}$ dehydrogenase forms the blue neutral form of the FAD semiquinone.

- The absorption spectrum of the FAD of $\mathrm{CODH}$ is $\mathrm{pH}$-dependent, probably due to ionization of an adjacent tyrosine residue.

- Electron transfer to the FAD is faster in CO dehydrogenase than in similar enzymes.

- Bicarbonate binds to the Mo- and Cu-containing binuclear site of CO dehydrogenase and abolishes all proton coupling in the EPR signal of enzyme partially reduced by dithionite. No coupling to ${ }^{13} \mathrm{C}$ is evident when ${ }^{13} \mathrm{C}$-labeled bicarbonate is used, suggesting the bicarbonate is not coordinated to the $\mathrm{Mo}(\mathrm{V})$ of the partially reduced binuclear cluster.

Keywords: Enzymology, CO dehydrogenase, Molybdenum, FAD

Abbreviations used: Bis-Tris, 2-[Bis(2-hydroxyethyl)amino]-2-(hydroxymethyl)propane-1,3-diol; HEPES, 2-[4-(2-hydroxyethyl)piperazin-1-yl]ethanesulfonic acid; Tris, 2-amino-2-hydroxymethylpropane-1,3-diol; 


\section{Introduction}

The carbon monoxide dehydrogenase from Oligotropha carboxidovorans is an $\mathrm{O}_{2}$-tolerant molybdenum- and copper-containing enzyme that catalyzes the oxidation of carbon monoxide to carbon dioxide according to Equation $1[1,2]$. It is both mechanistically and structurally distinct from the extremely $\mathrm{O}_{2}$-sensitive $\mathrm{Ni}$ - and $\mathrm{Fe}$-containing $\mathrm{CO}$ dehydrogenase from organisms such as Moorella thermoacetica or Methanosarcina barkerii [3].

$$
\begin{array}{cc}
E q 1: \quad \mathrm{CO}+\mathrm{H}_{2} \mathrm{O} \longrightarrow \mathrm{CO}_{2}+2 \mathrm{H}^{+}+2 \mathrm{e}^{-} \\
\left(\mathrm{E}^{\mathrm{o}}=-558 \mathrm{mV} \text { at } \mathrm{pH} 7\right)
\end{array}
$$

The enzyme is an $(\alpha \beta \gamma)_{2}$ hexamer with a large subunit (CoxL, $\left.89 \mathrm{kDa}\right)$ containing the binuclear active site, a medium subunit (CoxM, $30 \mathrm{kDa}$ ) with FAD and a small subunit (CoxS, 18 $\mathrm{kDa}$ ) containing two spinach ferredoxin-like [2Fe-2S] clusters [4]. Oxidation of carbon monoxide occurs at the binuclear center, with the reducing equivalents thus obtained reducing passed on to the FAD via the two iron-sulfur clusters, and finally on to the quinone pool [5]. On the basis of overall architecture and sequence homology, the $O$. carboxidovorans $\mathrm{CO}$ dehydrogenase belongs to the xanthine oxidase family of molybdenum-containing enzymes. It is unique among members of this large and broadly distributed family, however, in its binuclear active site, whose structure is shown in Figure 1 [6,7]. The overall configuration of the binuclear center is $\mathrm{LMo}^{\mathrm{VI}} \mathrm{O}_{2}-\mu \mathrm{S}-\mathrm{Cu}^{\prime}\left(\mathrm{OH}_{2}\right)$ $\mathrm{Cys}_{388}$, where $\mathrm{L}$ representing a bidentate pyranopterin cofactor common to all molybdenum enzymes other than nitrogenase (in this case present as the cytosine dinucleotide). The molybdenum has a square pyramidal coordination geometry with an apical $\mathrm{Mo}=\mathrm{O}$ and an equatorial plane consisting of the two sulfurs from the pyranopterin cofactor, an equatorial $\mathrm{Mo}=\mathrm{O}$ and a $\mu$ sulfido sulfur that bridges to the copper. The copper is trigonally coordinated, with a water molecule and Cys 388 of the CoxL subunit in addition to the bridging sulfur $[6,7]$.

In the present work we describe a series of physicochemical studies of the enzyme, focusing on its FAD and active site binuclear center. We identify the EPR signal of the FADH• semiquinone and characterize the unusual $\mathrm{pH}$-dependence of the FAD absorption spectrum, attempt to examine intramolecular electron transfer within partially reduced enzyme using a stopped-flow pH-jump method, and characterize the binuclear active site in complex with bicarbonate.

\section{Materials and methods}

\subsection{Materials}

CO was from Airgas. All other chemicals and reagents were obtained at the highest quality and purity commercially available and used without additional purification.

\subsection{Purification and enzyme assays}

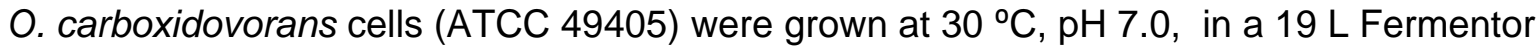
(BioFlo 415, New Brunswick) with minimal media and CO as the sole carbon and energy source $[1,8]$. CO was introduced in a 20/80 mixture of $\mathrm{CO}$ and air, with a total gas flow rate of $2.0 \mathrm{~L} / \mathrm{min}$. Cells were harvested in the late log phase $\left(\mathrm{OD}_{436}>6\right)$, washed with HEPES, $\mathrm{pH} 7.2$, and stored at $80{ }^{\circ} \mathrm{C}$ until needed. CO dehydrogenase was purified as described previously [8], using Q- 
Sepharose and Sephacryl S-300 FPLC. Enzyme concentration was determined from the absorbance at $450 \mathrm{~nm}$ using an $\varepsilon_{450}$ of $36 \mathrm{mM}^{-1} \mathrm{~cm}^{-1}$ per active site [9]; the purity was assessed by absorbance ratios $A_{280 / 450}$ of or less 5.5, $A_{450 / 420} \sim 1$ and $A_{450 / 550} \sim 2.9$. All enzyme preparations were reconstituted with sulfur and copper prior to use following the procedure of Resch et al. [9] as modified by Wilcoxen et al. [5]. After reactivation, enzyme was approximately $40 \%$ functional as determined from a comparison of the absorbance decrease at $450 \mathrm{~nm}$ upon reduction of enzyme with $\mathrm{CO}$ (which reduces only the fully functional enzyme) as compared to the absorbance change seen with dithionite (which reduces functional and nonfunctional enzyme indiscriminately) [5]. Unless otherwise stated, enzyme concentrations used are those of the functional enzyme, corrected for the amount of the nonfunctional form. Routine enzyme assays were performed at 25 ${ }^{\circ} \mathrm{C}$ using methylene blue $\left(\varepsilon_{615}=37.11 \mathrm{mM}^{-1} \mathrm{~cm}^{-1}\right)$ or $1-4$ benzoquinone $\left(\Delta \varepsilon_{247}\right.$ of $\left.20.2 \mathrm{mM}^{-1} \mathrm{~cm}^{-1}\right)$ as oxidizing substrate $[5,8]$.

\section{3. rapid-reaction kinetics}

Enzyme-monitored turnover experiments were performed using an Applied Photosystems SX-18MV stopped-flow apparatus. A typical experiment involved first making a solution of $\sim 25 \mu \mathrm{M}$ $\mathrm{CO}$ dehydrogenase in $50 \mathrm{mM}$ potassium phosphate buffer, $\mathrm{pH} 7.2$ anaerobic in a glass tonometer by alternately evacuating and flushing with Ar for $1 \mathrm{~h}$. Solutions of $1.0 \mathrm{M} \mathrm{1,4-benzoquinone} \mathrm{in} 50$ $\mathrm{mM}$ potassium phosphate buffer, $\mathrm{pH} 7.2$, were then bubbled with $\mathrm{CO}$ for twenty minutes. The two solutions were then mounted on the stopped-flow apparatus and mixed at $4^{\circ} \mathrm{C}$. Data was collected spectrophotometrically over a time course of two seconds and analyzed using both single wavelength and photodiode array detection at 450 and $550 \mathrm{~nm}$ using the Pro-Data SX and ProData Viewer software package by Applied Photosystems, Inc.

$\mathrm{pH}$ jump experiments aimed at observing the re-equilibration of reducing equivalents among the redox-active centers of partially-reduced $\mathrm{CO}$ dehydrogenase were performed as follows. A 30 $\mu \mathrm{M}$ solution of $\mathrm{CO}$ dehydrogenase in $50 \mathrm{mM}$ CAPS, $0.1 \mathrm{~N} \mathrm{KCl} \mathrm{pH} 10$ buffer was made anaerobic in a sealed tonometer by evacuating and flushing with Ar for $1 \mathrm{hr}$. A spectrum of the oxidized enzyme was recorded prior to partial reduction with sodium dithionite, monitoring progressive reduction spectrophotometrically by bleaching of the enzyme throughout the visible region. The tonometer was then mounted on to a stopped-flow apparatus, where it was mixed at $4^{\circ} \mathrm{C}$ with $400 \mathrm{mM}$ BisTris, $0.1 \mathrm{~N} \mathrm{KCl}, \mathrm{pH} 6.0$ buffer, monitoring the reaction spectrophotometrically over a timescale of $0.1 \mathrm{~s}$ using both diode array and single wavelength detection; in the latter case time courses were taken at 450 and $550 \mathrm{~nm}$ to follow electron re-equilibration between the Fe/S clusters and the flavin. The $\mathrm{pH}$ jump in the reverse direction was also performed, with the enzyme initially in $50 \mathrm{mM}$ BisTris, $0.1 \mathrm{~N} \mathrm{KCl}, \mathrm{pH} 6$ and mixed with $400 \mathrm{mM}$ CAPS, $0.1 \mathrm{~N} \mathrm{KCl}, \mathrm{pH} 10$.

\subsection{Electron paramagnetic resonance spectroscopy}

EPR spectra were recorded using a Brüker Instruments ER 300 spectrophotometer equipped with an ER $035 \mathrm{M}$ gaussmeter and an HP 5352B microwave frequency counter. The temperature was maintained at $150 \mathrm{~K}$ with a Brüker ER 4111VT liquid $\mathrm{N}_{2}$ cryostat. Samples of partially reduced enzyme were prepared by first making the enzyme (at a concentration on the order of $50 \mu \mathrm{M}$ ) anaerobic in $50 \mathrm{mM}$ HEPES, pH 7.2 in the presence of $400 \mathrm{mM}$ bicarbonate. Samples were then transferred anaerobically to Ar-flushed EPR tubes fitted with serum stoppers, and partially reduced by titration with a concentrated dithionite stock solution in $50 \mathrm{mM} \mathrm{Tris-HCl,} \mathrm{pH}$

7.0. Enzyme reduction was monitored by the absorbance decrease in the visible region as the FAD 
and iron-sulfur clusters became reduced, using a specially fitted holder for the EPR tube in the spectrophotometer (a Hewlett-Packard 8452A diode array instrument). Samples were then frozen in an ethanol/dry ice bath prior to transfer to a liquid nitrogen Dewar. EPR spectra were recorded at 9.45 GHz microwave frequency with $10 \mathrm{~mW}$ power and 5.0 Gauss modulation amplitude at $150 \mathrm{~K}$.

\section{Results and discussion}

\subsection{EPR characterization of the $F A D H \bullet$ semiquinone}

In an enzyme-monitored turnover experiment in which $10 \mu \mathrm{M}$ CO dehydrogenase in $50 \mathrm{mM}$ potassium phosphate buffer, $\mathrm{pH} 7.2$ was reacted with a solution of $1.0 \mathrm{mM} \mathrm{CO}$ and $0.5 \mathrm{mM} \mathrm{1,4-}$ benzoquinone, a typical transient at $450 \mathrm{~nm}$ (Figure 2, blue transient) exhibited the expected profile with three distinct phases: (1) a rapid approach to the steady-state (in this case an absorbance decrease due to partial reduction of the enzyme); (2) a prolonged steady-state phase in which the limiting substrate (in this case 1,4-benzoquinone, the oxidizing substrate) was consumed and the enzyme became progressively more reduced (with further loss of absorbance); and (3) a final phase in which the enzyme became fully reduced upon consumption of all the quinone by the remaining $\mathrm{CO}$ in excess. By contrast, the transient seen at $550 \mathrm{~nm}$ (Figure 2, red transient) clearly exhibited the transient accumulation of absorbance in the course of the steady-state phase of the time course. The transient absorption increase was likely due to the accumulation of the neutral $\mathrm{FADH} \cdot$ semiquinone, although no EPR signal for this species has been reported previously for CO dehydrogenase from $O$. carboxidovorans (it being noted, however, that a partially resolved EPR signal attributable to FADH• has been reported for the enzyme from Pseudomonas thermocarboxidovorans [10]). To determine whether this was the case, the enzyme was reexamined by EPR at $\mathrm{pH}$ 6.0, where FADH• accumulation is expected to be favored. The EPR sample was prepared by first making $200 \mu \mathrm{L}$ of $50 \mu \mathrm{M}$ CO dehydrogenase (in $50 \mathrm{mM}$ Bis-Tris buffer, $\mathrm{pH}$ 6.0) anaerobic by alternately flushing and evacuating with Ar for 1 hour. Enzyme was then transferred to an EPR tube and titrated with sodium dithionite until an increase of absorbance above $550 \mathrm{~nm}$ relative to the oxidized enzyme was observed. The sample was then frozen in liquid $\mathrm{N}_{2}$ and analyzed using EPR spectroscopy. EPR instrument settings at $150 \mathrm{~K}$ were $9.613 \mathrm{GHz}$ microwave frequency, 37 milliwatt microwave power, and 22.39 Gauss modulation amplitude. Figure 2 shows the resulting spectrum with the characteristic isotropic signal of FADH $\bullet$ at 3400 Gauss $(g=2)$ with a linewidth of about 20 Gauss, specifically indicative of a neutral semiquinone $[11,12]$. We conclude that the transient absorbance seen at $550 \mathrm{~nm}$ in the course of reductive titrations at low $\mathrm{pH}$ is due to the accumulation of $\mathrm{FADH} \bullet$ rather than a partially-reduced binuclear center.

\section{2. $p H$-dependent behavior of CO dehydrogenase}

\subsection{1 $\mathrm{pH}$ dependence of reductive titrations}

The EPR signal of FADH• only accumulates to any significant degree below $\mathrm{pH} 7.0$, reflecting the fact that the distribution of reducing equivalents within partially reduced $\mathrm{CO}$ dehydrogenase is $\mathrm{pH}$-dependent. In order to further investigate this $\mathrm{pH}$ dependence of the distribution of reducing equivalents within $\mathrm{CO}$ dehydrogenase, we next performed reductive titrations of the enzyme with sodium dithionite at high and low $\mathrm{pH} .20-25 \mu \mathrm{M}$ of $\mathrm{CO}$ dehydrogenase 
in either $50 \mathrm{mM}$ CAPS with $0.1 \mathrm{~N} \mathrm{KCl}, \mathrm{pH} 10$, or $50 \mathrm{mM}$ Bis-Tris with $0.1 \mathrm{~N} \mathrm{KCl}, \mathrm{pH}$ 6.0, was made anaerobic by alternately flushing and evacuating with Ar for $1 \mathrm{hr}$ in an anaerobic cuvette and then titrated stepwise to full reduction using sodium dithionite, following the titration spectrophotometrically. The results of such titrations at $\mathrm{pH} 6$ and 10 are shown in Figure 3 (panels $A$ and $B$, respectively). A careful examination of the region around $550 \mathrm{~nm}$ shows that at $\mathrm{pH} 6$ there is an initial increase in aborption early in the course of the titration that is absent in the titration at $\mathrm{pH}$ 10. The trend is made clearer in a plot of the fractional absorbance change at $550 \mathrm{~nm}$ (where only the iron-sulfur clusters contribute to the absorption change seen on reduction of the enzyme) versus that at $450 \mathrm{~nm}$ (where the FAD and two iron-sulfur cluster contribute approximately equally to the abosrbance change). The initial deflection of the titration down and to the right early in the course of the titration at $\mathrm{pH} 6.0$ is clearly evident, indicating that reduction of FAD, including formation of $\mathrm{FADH} \bullet$, initially precedes that of the iron-sulfur clusters at low $\mathrm{pH}$. Similar behavior has been observed in the closely related enzyme xanthine oxidase [13], and reflects the obligatory uptake of protons upon reduction of the FAD.

\subsection{2 $\mathrm{pH}$ dependence of the absorption spectrum of oxidized CO dehydrogenase}

In the course of conducting the above reductive titrations, it became evident that the absorption spectrum of oxidized $\mathrm{CO}$ dehydrogenase was $\mathrm{pH}$-dependent. The spectrum at $\mathrm{pH} 6$ closely resembled that seen at $\mathrm{pH} 7.2$, with an absorption maximum at $450 \mathrm{~nm}$, and shoulders at 420, 470, and $550 \mathrm{~nm}$ (58). At pH 10, however, a flattening in the 420-470 $\mathrm{nm}$ region was observed, as shown in Figure 4. The pH dependence of the aborption spectrum was abolished when the enzyme was reacted with diphenyliodonium ion, which specifically reacts with the isoalloxazine ring of the $\mathrm{FAD}$, rendering it redox-inert. We thus attribute the $\mathrm{pH}$-dependent spectral changes in oxidized native enzyme to its FAD site.

We further examined both the oxidase and dehydrogenase forms of bovine xanthine oxidoreductase, and found no $\mathrm{pH}$-dependence to their spectra in the fully oxidized state. On examining the protein environment of the FAD in CO dehydrogenase on the one hand and xanthine dehydrogenase on the other, it is to be noted that the environments are in a sense inverted, as illustrated in Figure 5: in CO dehydrogenase, Tyr 193 makes van der Waals contact with the re face of the isolloxazine ring with lle 101 on the si face, while in xanthine dehydrogenase lle 431 is on the re side of the isoalloxazine ring and Phe 337 on the si side. Most important, however, is the presence of the ionizable tyrosine immediately adjacent to the FAD of CO dehydrogenase, and its ionization over the $\mathrm{pH}$ range examined here is most likely the reason for the $\mathrm{pH}$ dependence of the flavin component of the enzyme's absorption spectrum.

\subsection{Electron transfer within CO dehydrogenase}

Given the $\mathrm{pH}$ dependence of the distribution of reducing equivalents within $\mathrm{CO}$ dehydrogenase as demonstrated in Section 3.2.1, we next employed a $\mathrm{pH}$-jump protocol we have employed in other systems [13-15] that involves preparing partially reduced enzyme in dilute buffer at one $\mathrm{pH}$ and then mixing it with more concentrated buffer at another $\mathrm{pH}$ in a stopped-flow apparatus. The redistribution of reducing equivalents driven by the $\mathrm{pH}$ change. Using this protocol with xanthine oxidase, the electron redistribution has been shown to be biphasic, with a faster process involving electron equilibration between the molybdenum and iron-sulfur clusters occurring in the mixing dead-time, and a slower single-exponential process involving electron equilibration between the iron-sulfur clusters and FAD occurring with a rate constant between 150 and $330 \mathrm{~s}^{-1}$, 
depending on the final $\mathrm{pH}[13,14]$. As the overall structures of $\mathrm{XO}$ and $\mathrm{CO}$ dehydrogenase are very similar as regards the disposition of the several redox-active centers in the polypeptide, we may expect to see similar rates of intramolecular transfer.

Unfortunately, efforts to observe the kinetics of the reequilibration of reducing equivalents in $\mathrm{CO}$ dehydrogenase using this $\mathrm{pH}$-jump protocol were unsuccessful. For both $\mathrm{pH}$ 10-to-6 and 10-to6 jumps, all spectral changes took place in the mixing dead-time ( $2 \mathrm{~ms})$, placing a lower limit of $\sim 1000 \mathrm{~s}^{-1}$ on the rate constant for equilibration between the FAD and iron-sulfur clusters and demonstrating that electron transfer rates within $\mathrm{CO}$ dehydrogenase are substantially faster than in xanthine oxidase. It is the FAD/FADH • couple that is involved in the slower reequilibration process, and it has been shown with xanthine oxidase that the oxidation of the FADH• exhibits a large solvent isotope effect [13], indicating that the proton is in motion as the system traverses the electron-transfer transition state. Such proton-coupled electron transfer is now recognized as being a general phenomenon [16,17], and the above-mentioned tyrosine may serve to facilitate the protonation/deprotonation steps necessarily associated with reduction/oxidation of the flavin of $\mathrm{CODH}$, thereby accelerating electron transfer into and out of the flavin as compared to xanthine oxidase.

\subsection{EPR of the binuclear center in complex with bicarbonate}

We have previously reported that the EPR signal of the binuclear active site in CO dehydrogenase that has been partially reduced by dithionite is perturbed upon addition of bicarbonate, most notably in the abolishment of all proton hyperfine coupling (coupling to at least two inequivalent protons is evident in the signal in $\mathrm{H}_{2} \mathrm{O}$ ) [18]. It has been suggested that bicarbonate binds at the copper ion of the binuclear center and displaces the water molecule (and possibly also the equatorial -OH group coordinated to the molybdenum ion) that otherwise contributes the magnetically coupled protons evident in the EPR signal of dithionite-reduced enzyme. The nature of the bicarbonate complex has taken on mechanistic implications since it has been suggested [19] in a recent computational study that bicarbonate rather than $\mathrm{CO}_{2}$ is the actual product of the enzymic reaction, being complexed with the molybdenum ion of the binuclear center via a catalytically introduced oxygen immediately prior to dissociation.

In order to further assess the mechanistic relevance of the bicarbonate complex, we have examined its EPR signal when generated with ${ }^{13} \mathrm{C}$-labeled bicarbonate. Figure 5 shows a comparison of the binuclear EPR signal seen with dithionite-reduced enzyme in $\mathrm{H}_{2} \mathrm{O}$ in the absence of bicarbonate $(A)$, in $\mathrm{D}_{2} \mathrm{O}$ in the absence of bicarbonate $(\mathrm{B})$, in $\mathrm{H}_{2} \mathrm{O}$ in the presence of $500 \mathrm{mM}{ }^{12} \mathrm{C}$ bicarbonate $(C)$ and in $\mathrm{H}_{2} \mathrm{O}$ in the presence of $500 \mathrm{mM}{ }^{13} \mathrm{C}$-bicarbonate (D). The first three spectra are in good agreement with those previously reported [18]. The final spectrum (D), seen with ${ }^{13} \mathrm{C}$ labeled formate, manifests no resolved hyperfine splitting due to the $\mathrm{I}=1 / 2$ nuclear spin of ${ }^{13} \mathrm{C}$. Future ENDOR studies will more precisely characterize the nature of the ${ }^{13} \mathrm{C}$ coupling, but we observe that the proximal carbon in compounds coordinated to the molybdenum via oxygen in the related enzyme xanthine oxidase are usually fairly strongly coupled [as reviewed in 20], and on the basis of the absence of any obvious coupling seen here it appears unlikely that bicarbonate is bound to what is formally a $\mathrm{Mo}(\mathrm{V})$ in the partially reduced binuclear cluster. We emphasize in any case that the EPR signal of bicarbonate-complexed $\mathrm{CO}$ dehydrogenase in no way resembles that seen in the course of catalysis with $\mathrm{CO}$ as substrate, and is unlikely to arise from a catalytic intermediate [8]. 


\section{Conclusions}

In the present work, we have characterized the blue neutral semiquinone of the FAD site in $\mathrm{CO}$ dehydrogenase, and attributed the $\mathrm{pH}$-dependence of the enzyme's oxidized spectrum and behavior during reductive titrations to the FAD site. the contrasting behavior of the FAD sites of CO dehydrogenase and bovine xanthine oxidoreductase is attributed to the presence of an ionizable tyrosine (Tyr 377 of the CoxM subunit) adjacent to the FAD in CO dehydrogenase. This residue may also be responsible for the much faster proton-coupled electron transfer involving the FAD that is seen in CO dehydrogenase as compared to xanthine oxidoreductase. Finally, we have also examined the EPR signal of the enzyme's Mo- and Cu-containing binuclear center in complex with ${ }^{13} \mathrm{C}$-labeled bicarbonate, and find no evident coupling to the ${ }^{13} \mathrm{C}$ nucleus. While more definitive ENDOR spectroscopic studies are forthcoming, it seems unlikely that the bicarbonate is coordinated to the $\mathrm{Mo}(\mathrm{V})$ ion of the partially reduced binuclear center.

\section{Acknowledgements}

This work was supported by the US Department of Energy (DE-FG02-13ER16411 to R.H.). 


\section{References}

1. O. Meyer, H.G. Schlegel. Arch. Microbiol. 118 (1978) 35-43.

2. O. Meyer, H.G. Schlegel. J. Bacteriol. 141 (1980) 78-80.

3. S. Ragsdale,E. Pierce. Biochim. Biophys. Acta 1784 (2008) 1873-1898.

4. B. Santiago, U. Schubel, C. Egelseer, O. Meyer. Gene 236 (1999) 115-124.

5. J. Wilcoxen, B. Zhang, R. Hille. Biochemistry 50 (2011) 1910-1916.

6. H. Dobbek, L. Gremer, O. Meyer, R. Huber. Proc. Natl. Acad. Sci. USA 96 (1999) 8884-8889.

7. H. Dobbek, L. Gremer, R. Kiefersauer, R. Huber, O. Meyer. Proc. Natl. Acad. Sci. USA 99 (2002) 15971-15976.

8. B. Zhang, C.F. Hemann, R. Hille. J. Biol. Chem. 285 (2010) 12571-12578.

9. M. Resch, H. Dobbek, O. Meyer. J. Biol. Inorg. Chem. 10 (2005) 518-528.

10. P. Hänzelmannn, B. Hofmann, S. Meisen, O. Meyer. FEMS Microbiol. Lett. 176 (1999) 139145.

11. H. Beinert. Biochim. Biophys. Acta 20 (1956) 588-590.

12. V. Massey, G. Palmer. Biochemistry 5 (1966) 3181-3189.

13. R. Hille. Biochemistry 30 (1991) 8522-8529.

14. R. Hille, V. Massey. J. Biol. Chem. 261 (1986) 1241-1247.

15. R.J. Rohlfs, R. Hille. J Biol. Chem. 266 (1991) 15244-15252.

16. A. Migliore, N.F. Polizzi, M.J. Therien, D.N. Beratan. Chem. Rev. 114 (2014) 3381-3465.

17. D.R. Weinberg, C.J. Gagliardi, J.F. Hull, C.F. Murphy, C.A. Kent, B.C. Westlake, A> Paul, D.H. Hess, D.G. McCafferty, T.J. Meyer. Chem. Rev. 112 (2012) 4016-4093.

18. J. Wilcoxen, R. Hille. J. Biol. Chem. 288 (2013) 36052-36060.

19. B.W. Stein, M.L. Kirk. Chem. Commun. 50 (2014) 1104-1106.

20. R. Hille. EPR studies of xanthine oxidoreductase and other molybdenum-containing hydroxylases Ch. 5. In: Biological Magnetic Resonance vol. 29, Metals in Biology: Applications of High-Resolution EPR to Metalloenzymes. (G. Hanson and L. Berliner, Jr., eds.) Springer, Berlin, 2010, pp. 91-121. 
Figure legends.

Figure 1. Structure of the binuclear center of $\mathrm{CO}$ dehydrogenase. The structure is of the fully oxidized enzyme (PDP 1N5W). The EPR-active species is of the one-electron reduced from, which is formally $\mathrm{Mo}(\mathrm{V}) / \mathrm{Cu}(\mathrm{I})$. The pyranopterin cofactor coordinated to the molybdenum is present as the dinucleotide of cytosine.

Figure 2. An enzyme-monitored turnover experiment with $\mathrm{CO}$ dehydrogenase. The reaction involved mixing $10 \mu \mathrm{M} \mathrm{CO}$ dehydrogenase with $500 \mu \mathrm{M}$ benzoquinone and $1.0 \mathrm{mM} \mathrm{CO}$ under anaerobic conditions in $0.1 \mathrm{M} \mathrm{P}$, $\mathrm{pH} 7.8,25^{\circ} \mathrm{C}$. The absorbance change was monitored at $450 \mathrm{~nm}$ (red, left $\mathrm{y}$-axis) and $550 \mathrm{~nm}$ (blue; right y-axis). The additional long-wavelength absorbance at 550 $\mathrm{nm}$ that builds up in the 1.0 - 1.5 second range has the characteristics expected for the accumulation of the EPR-active state of the enzyme's binuclear center. Reaction conditions were $50 \mathrm{mM} \mathrm{KP}, \mathrm{pH} 7.2,25^{\circ} \mathrm{C}$.

Figure 3. The EPR spectrum of the FADH• of $\mathrm{CO}$ dehydrogenase partially reduced by sodium dithionite. The buffer conditions were $50 \mathrm{mM}$ Bis-Tris, pH 6.0. EPR instrument settings at $150 \mathrm{~K}$ were $9.613 \mathrm{GHz}$ microwave frequency, 37 milliwatt microwave power, and 22.39 Gauss modulation amplitude. The resulting spectrum showed a nearly isotropic signal at 3400 Gauss $(g=2)$ with a linewidth of about 20 Gauss, indicative of a neutral semiquinone.

Figure 4. The $\mathrm{pH}$ dependence of reductive titrations of $\mathrm{CO}$ dehydrogenase. A, stepwise reduction of $\mathrm{CO}$ dehydrogenase with sodium dithionite in $50 \mathrm{mM}$ bis-Tris with $0.1 \mathrm{~N} \mathrm{KCl}, \mathrm{pH}$ 6. $\mathbf{B}$, stepwise reduction of $\mathrm{CO}$ dehydrogenase with sodium dithionite in $50 \mathrm{mM} \mathrm{CAPS}$ with $0.1 \mathrm{~N} \mathrm{KCl}, \mathrm{pH} 10$. At both $\mathrm{pH}$ extremes, the uppermost spectrum is of oxidized enzyme, while the lowest spectrum is of fully reduced enzyme at completion of the titration. $\mathbf{C}$, plot of the fractional absorbance change at $550 \mathrm{~nm}$ versus that $450 \mathrm{~nm}$ for the titration at $\mathrm{pH} 10$ (black) and $\mathrm{pH} 6$ (red).

Figure 5. The $\mathrm{pH}$ dependence of the spectrum of oxidized $\mathrm{CO}$ dehydrogenase. UV-visible spectra showing $25 \mu \mathrm{M}$ oxidized $\mathrm{CO}$ dehydrogenase in either $50 \mathrm{mM}$ bis-Tris with $0.1 \mathrm{~N} \mathrm{KCl}, \mathrm{pH} 6$ (red) or in $50 \mathrm{mM}$ CAPS with $0.1 \mathrm{~N} \mathrm{KCl}, \mathrm{pH} 10$ (blue). Inset, spectral difference of oxidized enzyme at pH 6 minus that 10.

Figure 6. The environment of the FAD in CO dehydrogenase (left) and bovine xanthine dehydrogenase (right). The PDB files used to construct the figure were 1N5W and 1FO4, respectively. Note the inversion of the isoleucine and aromatic residues (Tyr 193 in CO dehydrogenase, Phe 337 in xanthine dehydrogenase, relative to the isoalloxazine ring of the FAD in the two structures.

Figure 7. EPR signals of the binuclear center partially reduced by dithionite. The spectra are for: A, dithionite-reduced $\mathrm{CO}$ dehydrogenase in 50 mM HEPES, $\mathrm{pH} 7.2$; $\mathbf{B}$, dithionite-reduced $\mathrm{CO}$ dehydrogenase in 50 mM HEPES, pD 7.2; C, dithionite-reduced $\mathrm{CO}$ dehydrogenase in $1 \mathrm{M}$ $\mathrm{NaH}^{12} \mathrm{CO}_{3}$ in $50 \mathrm{mM}$ HEPES, $\mathrm{pH}$ 7.2; and $\mathbf{D}$, dithionite-reduced $\mathrm{CO}$ dehydrogenase in $1 \mathrm{M} \mathrm{Na}$ $\mathrm{H}^{13} \mathrm{CO}_{3}{ }^{-}$in $50 \mathrm{mM}$ HEPES, $\mathrm{pH} 7.2$. 
Figure 1.

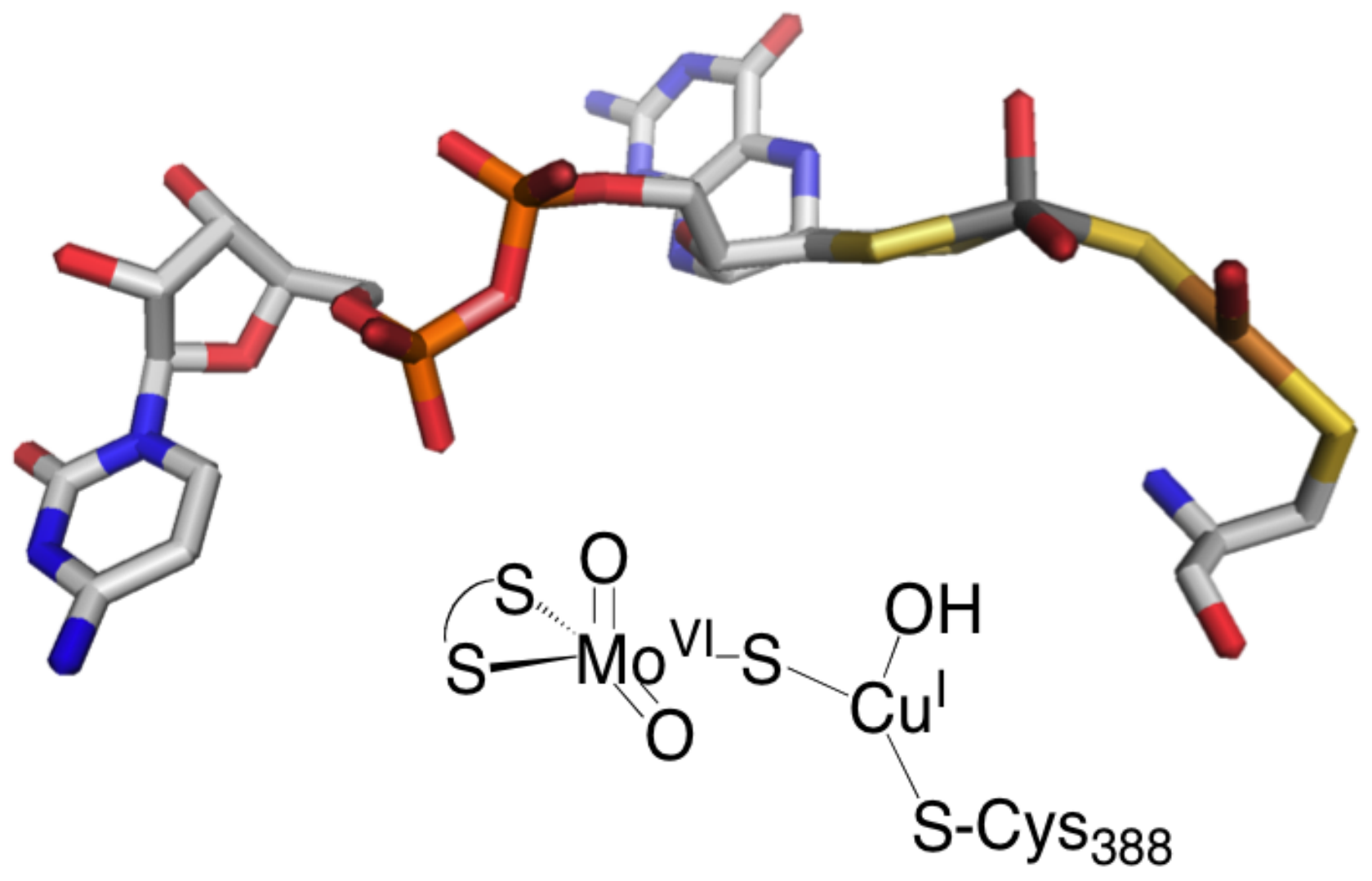


Figure 2.

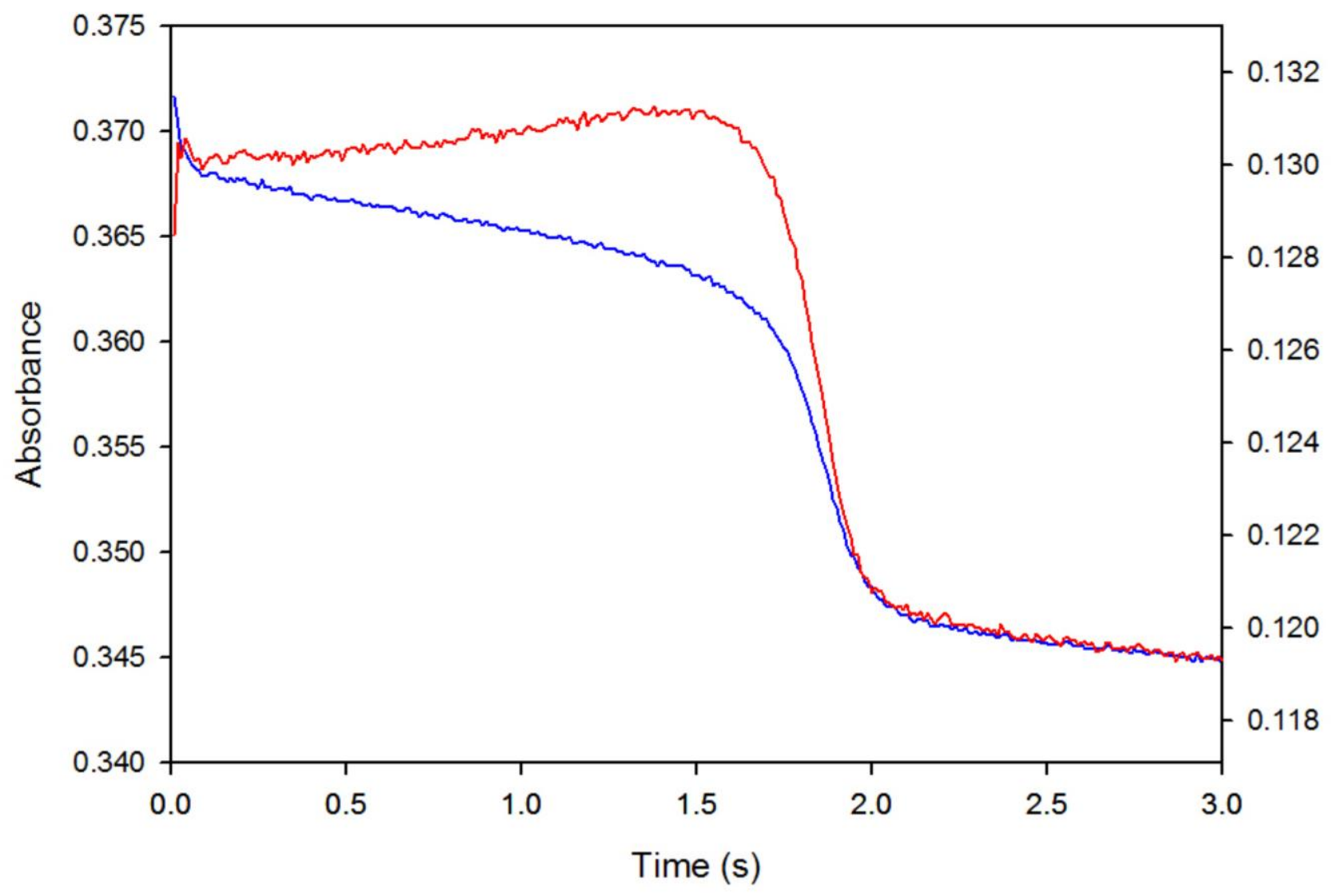


Figure 3.

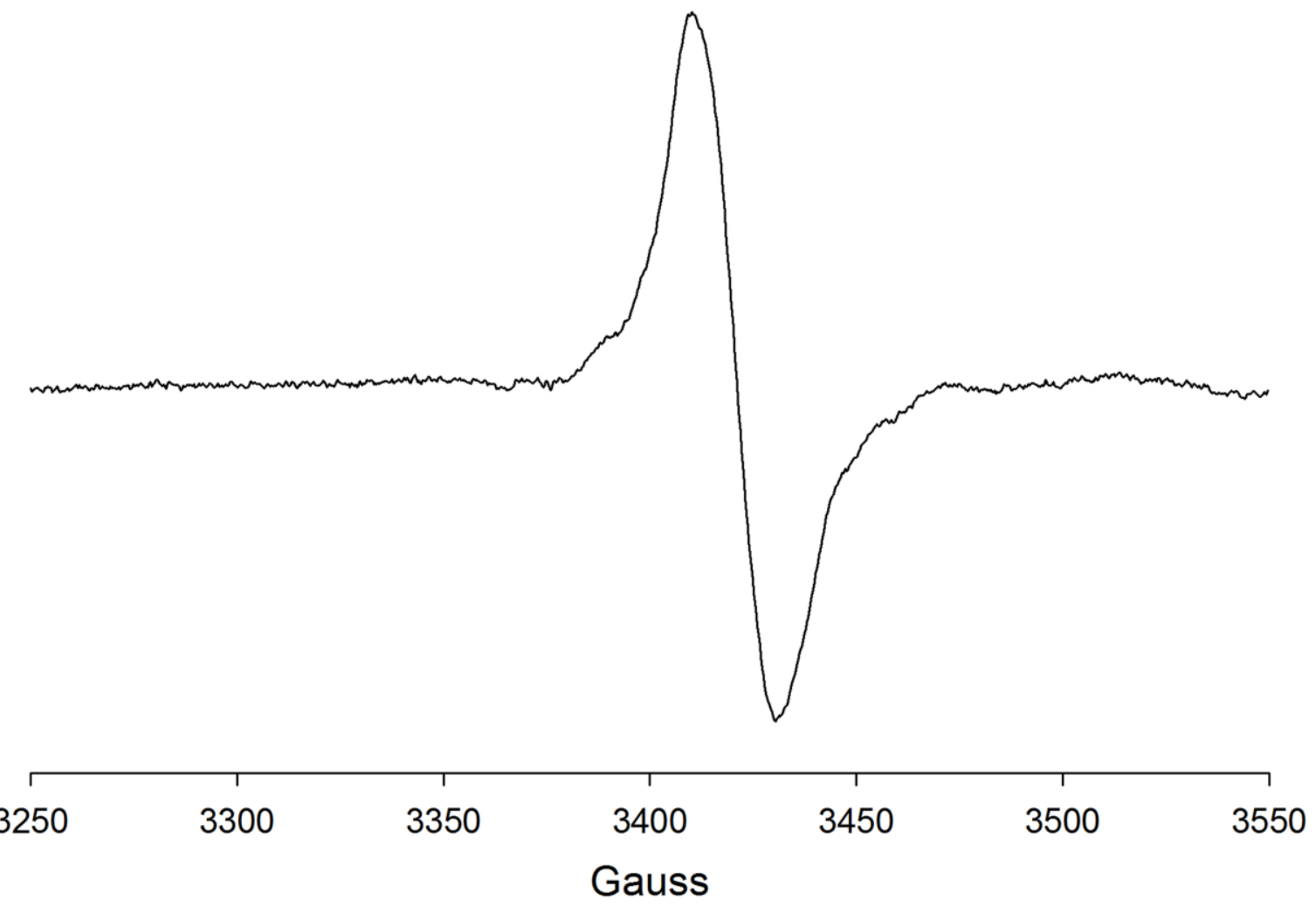


Figure 4.

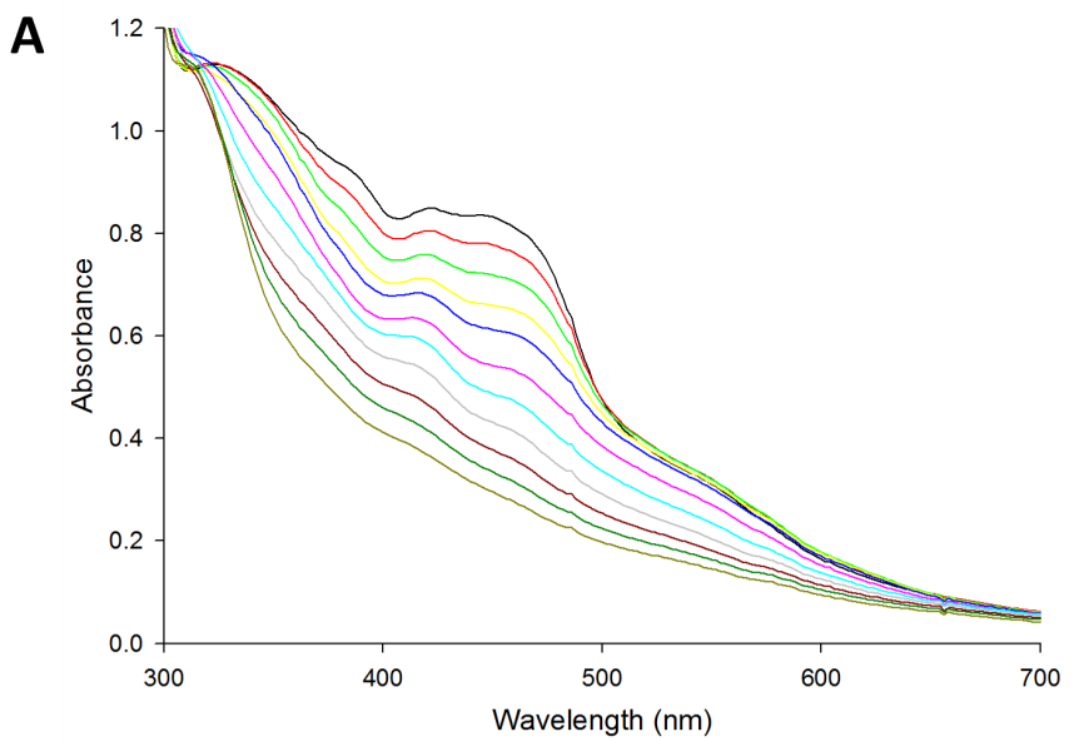

B
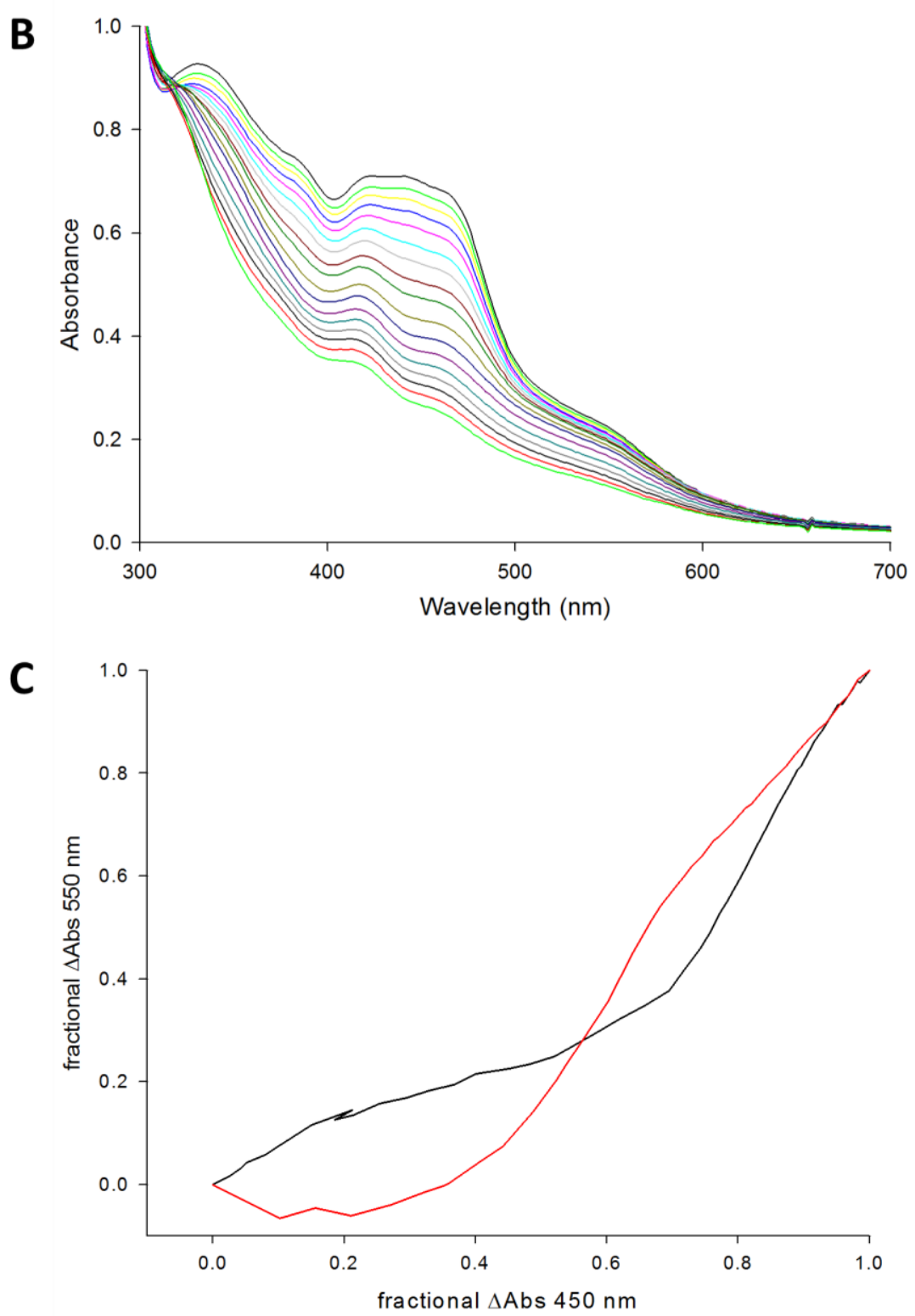
Figure 5.

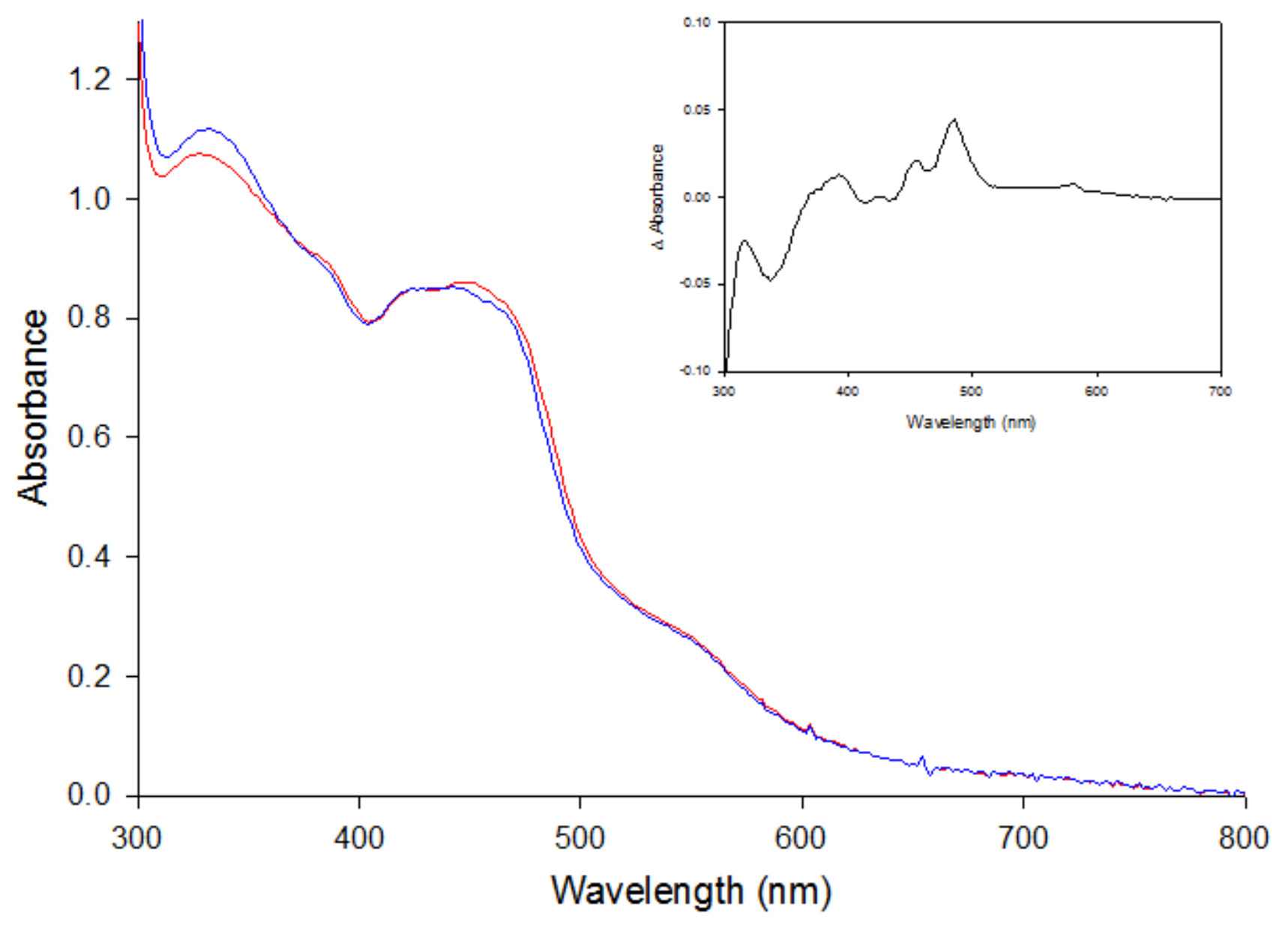


Figure 6.
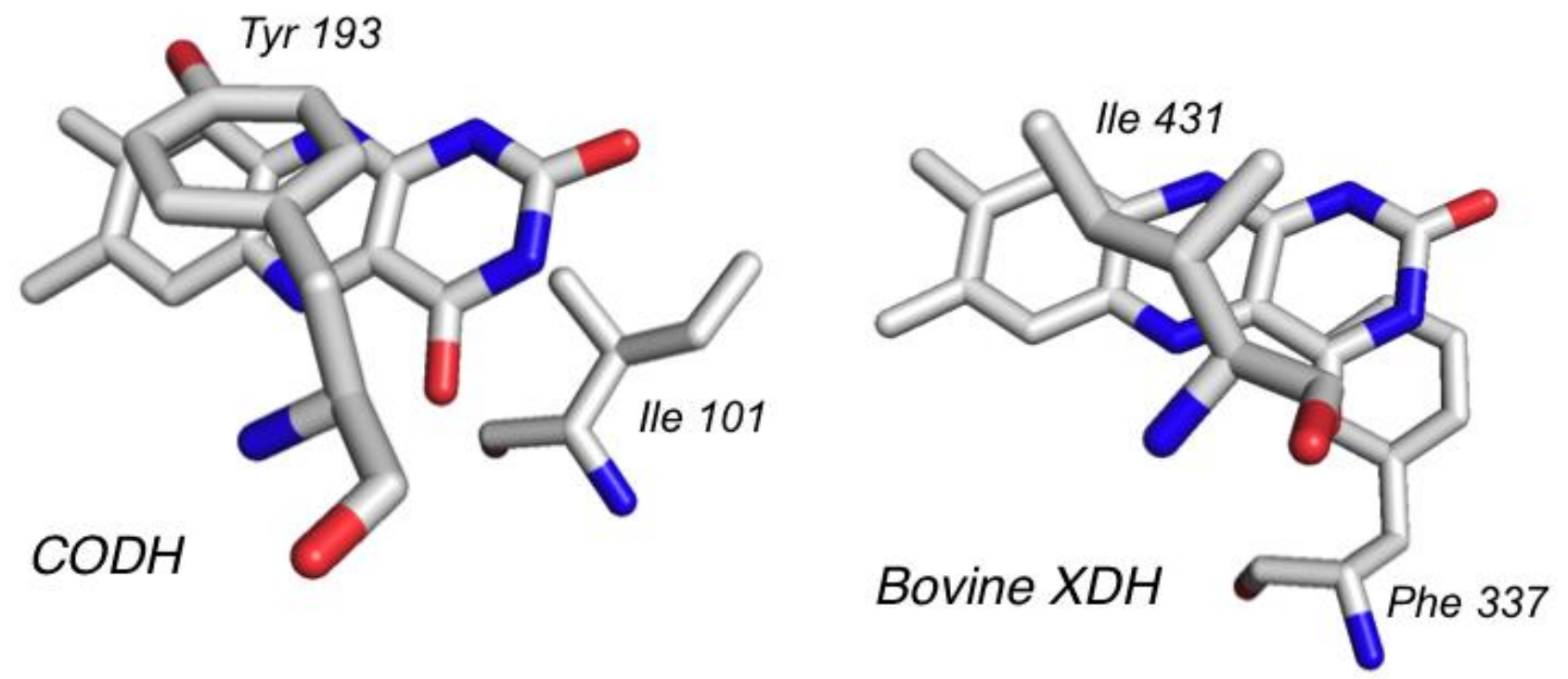
Figure 7.
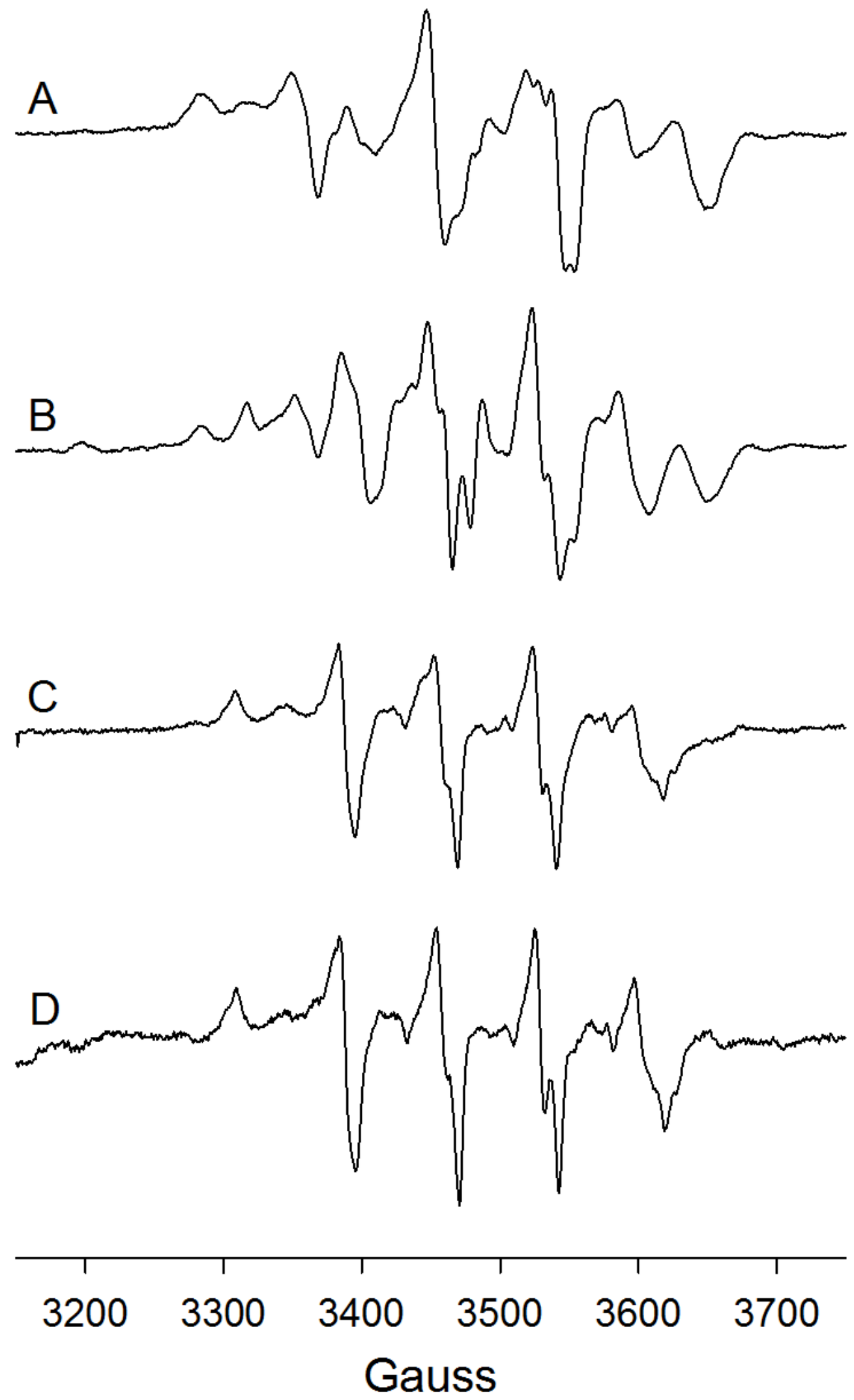


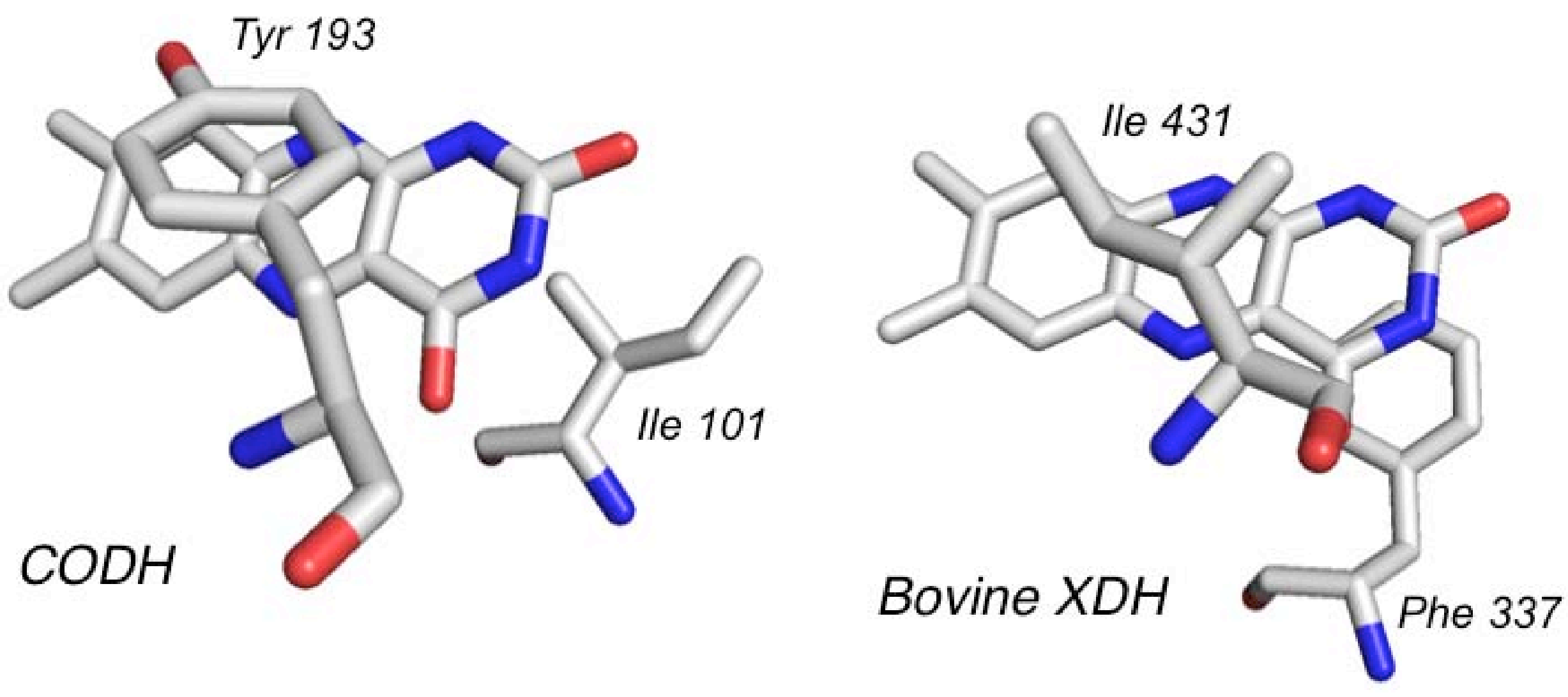

